\title{
New studies of wild-growing grapes of Kuban: ecology, morphology, variability
}

\author{
I.V. Gorbunov*, and A.A. Lukyanov
}

Branch of the Federal State Budget Scientific institutions North Caucasian Federal Scientific Center of Horticulture, Viticulture, Winemaking, Anapa, Russia

\begin{abstract}
The purpose of this scientific work was to find and study the variety of wild grapes as future promising sources of selection and valuable traits on the example of the territory of the natural reserve «Red Forest". Analysis of modern scientific literature on the study of Vitaceae Juss. family biodiversity showed that there is practically no scientific information on agrestic Kuban forms and autochthones of grapes. This article represents the beginning of a new large research work on the study of wild Kuban grapes under study in the territory of Krasnodar Krai, in particular, in the state natural reserve "Red Forest". The following methods were used in the work: route reconnaissance (during expeditions), traditional geobotanical and ampelographic, analytical. 5 isolated populations of agrestic grapes have been found on the territory of the "Red Forest" nature reserve. For the first time, these forms were studied and described by the ecological and geographical growth conditions and morphological traits of vegetative and generative spheres of grape plants. Significant variability of some indicators has been revealed. The presence of damage by pests and diseases was not visually detected. Hypothetically, these isolated grape populations may belong to Vitis vinifera ssp. Silvestris Gmel. or its variation var. Tipica Negr. (wild forest grapes). Samples were taken for further genetic analysis. This research was carried out within the framework of the RFFR grant project (contract No.19-416-230025).
\end{abstract}

\section{Introduction}

Genus Vitis L. (Vitaceae Juss. family) includes about 70 woody lianas distributed mainly in temperate areas of the Northern Hemisphere [1]. Wild grapes -Vitis vinifera ssp. silvestris Gmel. and its variations are forest clambering plants growing in separate populations or even single plants.

According to literary data of world studies, an agrestic sub-species of cltivated grapes (Vitis vinifera ssp. silvestris Gmel.) is an ancestor of existing cultivars [2-4]. It is a longliving species that can reach 300 years of age. The bark is greyish-brown or red-brown, thinly furrowed. Leaves are alternate, of different shapes - pentagonal, round or nodular, $5-9 \mathrm{~cm}$ long, 3 (5) -lobed, strongly or weakly incised, unevenly scalloped along the edge, with a broad (less often narrow) open petiolate, most of the flat bottom; the pubescence of the

\footnotetext{
* Corresponding author: wunsch27@mail.ru
} 
underside of the formed leaf is cotton, bristling or mixed, of varying intensity, but predominantly strongly or moderately pubescent. The flowers are dioecious. Staminate flowers with long stamens and rudimentary seed-bud. In pistille flowers, the stamen threads are short, bent to the side. The inflorescences are loose, of medium length. During fruiting, the bunches are loose, branched, cemuous, $10-15 \mathrm{~cm}$ long. The berries are usually black or reddish-black, globular, 6-8 (10) $\mathrm{mm}$ in diameter. The skin is dense with juicy pulp, usually sour or sour sweet taste. The grape seeds are very small, ovate, greyish-reddish or reddish brown with a short spout up to $1 \mathrm{~mm}$ long. There can be from 1 to 4 pcs. of seeds in one berry. Wild grape forms bloom in May - June, fruits ripen in September.

Grapes are considered the only species of cultivated plants that has Eurasian aboriginal origin, which appeared about 65 million years ago [5]. Taking a look into the history, it was divided into subspecies much later and it was associated with the morphological features of the grape [6]. In principle, grape is a unique plant, both because it is the main agricultural crop and because it has ancient historical links with the development of human culture and civilization.

Aborigines and agrestic grapes from various geographical zones of viticulture are the most valuable material of the gene pool and selection of this crop. Their study, along with molecular genetic analyses, provides an opportunity to further reveal the question of grape origin more or less close or distant genotypes.

In the literature we can find scientific information concerning Crimean, Dagestan, Don and other aboriginal forms of grapes [7-11]. But information on agrestic or autochthonous Kuban forms is practically absent. Such research was carried out for the first time in the territory of the state natural reserve "Red Forest".

Thus, this article reflects the results of new scientific researches - namely, ecologicalbiological and morphological features of agrestic grapes carried out on the territory of natural reserve "Red Forest". It is important to note that this is only the beginning of many years of research work on the origin study of agrestic Kuban grapes and sources identification among them; and in the future, identifying donors of sustainability to various kinds of biotic and abiotic environmental factors. And the ultimate goal of this study is to attract isolated stable agrestic forms in the selection process, allocation of new resistance sources to biotic and abiotic environmental factors and replenishment of the grape gene pool.

Purpose of the study. To search and study new Kuban agrestic forms of the Vitis L. genus growing on the territory of Krasnodar Krai in the state natural reserve "Red Forest" and are of great scientific interest for grape genetics and breeding.

Research objectives:

- to find agrestic forms of grapes in the territory of the natural reserve "Red Forest";

- to make a detailed description of their ecological growing conditions;

- to measure the main morphometric parameters of the vegetative and generative spheres of found grape plants;

- to study the variability of the main morphological traits of agrestic grapes at endogenous and inter-population levels;

- to carry out sampling from agrestic vines for further DNA analysis to determine closer and more distant genotypes of the studied grape plants.

\section{Materials and methods}

The study of ecological, biological, and morphological features of agrestic grape forms was carried out during expeditions in 2020 on the territory of the state natural reserve "Red Forest". This research was carried out within the framework of the RFFR grant project (contract No.19-416-230025). 
Methods of research - route reconnaissance, traditional geobotanical [12]. The followng was studied: relief of habitats, structure and floral composition of phytocenoses, vegetation. At the same time, morphological indicators of vegetative and generative spheres of agrestic grapes' plants were investigated [13]. More volatile morphological traits of the studied agrestic grapes' plants have been identified.

Wild grape plants were photographed in general view and in detail - the young shoot crown, the inner and outer sides of young and formed leaves, the bark of the central shoot (vine), etc. [14-15].

Samples (apical part of young shoot) were taken for molecular genetic analysis of the studied grape forms.

\section{Results and discussion}

The climate type of the reserve territory can be defined as Mediterranean with the influence of moderate latitudes climate. The average annual air temperature is $12.1 \ldots 12.2{ }^{\circ} \mathrm{C}$, the average temperature of January is $2 \ldots 3^{\circ} \mathrm{C}$, July $-23.3 \ldots 23.5^{\circ} \mathrm{C}$. The average annual precipitation is in the range of $570-700 \mathrm{~mm}$.

The Red Forest State nature reserve has an area of 5232.1 hectares. This is one of the largest forest areas of the flat steppe part of the Krasnodar Krai representing the remains of forest areas, which once framed along its right bank the Kuban riverbed to its very delta in a wide strip. Currently it looks like an island, which is washed by its waters for 6 kilometers. Plantations of natural origin are represented by pedunculate oak, which is the main forestforming species of this massif and includes fresh and moist forest type groups. The companions of oak are: European ash (Fraxinus excelsior), hornbeam (Carpinus betulus), hedge maple (Acer campestre), Tatarian maple (Acer tataricum), Caucasian pear (Pyrus caucasica), oriental apple tree (Malus orientalis), elm. The age of oak plantings ranges from 60 to 100 years. The average diameter is $24-28 \mathrm{~cm}$, the maximum is $44 \mathrm{~cm}$. Average height of plantings - $24.0-28.5 \mathrm{~m}$. Planting density - 0.7 units, growth class -2 .

Currently, a significant part of the oak stands has been replaced for various reasons by European ash, which is a stable stand type derived from oak. The age of ash stands of natural origin is $60-80$ years. Its average height varies from 23.0 to 29.0 meters with a diameter of $18-28 \mathrm{~cm}$, growth class -1 . Older trees are found. In the moist forest types group, abele and white willow are singly mixed in the composition of plantations. Within the "Red Forest" forest area there are artificial plantings of English oak, as well as English oak and European ash. Their age is 40-50 years old. Height - 18-20 meters. There is no underwood within forest stands. There is a partial ramping in mixed oak-ash and ash stands (Table 1).

Table 1. Ecological-geographical habitats characteristics of the studied populations of agrestic grapes

\begin{tabular}{|l|l|l|l|l|l|l|}
\hline It.No. & \multicolumn{1}{|c|}{ Location } & Relief & $\begin{array}{l}\text { Slope gradient, } \\
\text { degr. }\end{array}$ & $\begin{array}{l}\text { Slope } \\
\text { direction }\end{array}$ & Vegetation type & \multicolumn{1}{|c|}{ Soil type } \\
\hline 1 & territory of the reserve & plain & 0 & $-*$ & oak-ash forest & brown turf carbonate \\
\hline 2 & $\begin{array}{l}\text { the floodplain of the old } \\
\text { Kuban riverbed }\end{array}$ & dish & $2-3$ & SW & ash forest & brown carbonate \\
\hline 3 & $\begin{array}{l}\text { the floodplain of the old } \\
\text { Kuban riverbed }\end{array}$ & dish & $2-3$ & SW & ash forest & brown carbonate \\
\hline 4 & $\begin{array}{l}\text { the floodplain of the old } \\
\text { Kuban riverbed }\end{array}$ & dish & $2-3$ & SW & ash forest & brown carbonate \\
\hline 5 & territory of the reserve & plain & 0 & - & oak-ash forest & brown turf carbonate \\
\hline
\end{tabular}

Note: * no slope, flat area

The underwood is well-present and represented by: cornelian cherry, southern dogwood, Crataegus monogyna and Crataegus pentagyna, common filbert, common barberry, European elder, Viburnum opulus, briar, Rubus caesius, cherry-plum, sloe thorn, 
Euonymus europaea, etc. In floodplain massifs, woodland grape can be found as liana representative, which sometimes forms thick, difficult thickets, less often grows along the edges. Common hops can be found inn the part near riverbed.

Grass cover in closed forest array does not form ramping. Total projective cover is $30 \%$, can reach $70 \%$ in canopy windows. Composition: Violaceae sylvatica, purple gromwell, wood spurge, common avens, herb-robert geranium, catchweed, damewort. In some places, nettle development is observed in the form of plant sinusia; common avens, whitespot betony, Calystegia silvatica, bindweed and others are present in nettle thicket. Paris circaea and wartwort usually grow in shady places; on the edges, near the paths and roads - wood cerastium, horsemint, crownvetch, common Saint-John's wort, Dactylis glomerata.

Underwood is represented by specimens: European ash - 5.0 thousand pcs./ha, English oak - 1,8 thousand pcs./ha, hedge maple - 2.0 thousand pcs./ha, which is mainly connected to the canopy windows, as well as to the edge part of the stands.

As a result of expeditions, five populations of agrestic grape forms have been found, which differ from each other in morphological traits of vegetative and generative spheres. Populations No. 2 - 4 grow along the old channel of the Kuban River, which is several kilometers long; they are at a short distance from each other and have different morphological indicators of vegetative organs. All grape plants have a great age judging by the vine diameter (from $7 \mathrm{~cm}$ and above) and its repeated death and revival. Populations No.1 and No.5 are far isolated from each other and from previous populations (more than $2 \mathrm{~km}$ ) and have significant differences both between each other and in comparison with populations No.2, No.3 and No.4.

Population No.1. Has typical morphological traits of agrestic grapes, namely: open or slightly open apex (crown) of young shoot, weak degree of cotton and medium bristly pubescence of young shoot crown, strong pubescence of the lower and upper sides of young and formed leaves, strongly dissected lamina with deep upper lateral cuts. Visually the plants in this population have a healthy appearance, no pests and diseases were found, they were fully flowered and fruited. Bunches of this population grape plants are small, loose. The berries are small, juicy with a thick peel, had a black color and a sweet tart taste in biological ripeness, but with a pleasant freshness. The ripening of berries was observed in the second decade of September. On average there were 2 seeds per berry, small, rounded, reddish-brown.

Population No.2. It has the following morphological features: a slightly open or half-open apex (crown) of the young shoot, a high degree of cotton and bristly pubescence of the young shoot crown and young leaf, the average degree of cotton pubescence of the lower and upper side of the formed leaf, the lamina can be pentagonal in shape with very deep upper lateral cuts and round shape almost without cuts. Plants in a given population have endogenous variability in leaf shape and upper lateral cuts. Visually pests and diseases were not found. The bunches are small and very loose. Berries are small, rounded, juicy with thick peel, reddish-black or black, with a sweet and sour taste and moderate tartness. The ripening of berries took place in the second decade of September. There were 1-2 seeds per berry, they are small, rounded, grayish brown.

Population No.3. Features in the morphology of grape plants in this population are: slightly open young shoot crown, high degree of cotton and bristly pubescence of young shoot crown, as well as lower and upper sides of young and formed leaf, strongly dissected 3-blade lamina with very deep upper lateral cuts of deltoid or pentagonal shape. Visually the plants in this population have a healthy appearance, no pests and diseases were found, they were fully flowered and fruited. Bunches of this population grape plants are small, loose. Berries are small, had a reddish-black color and a sour and sweet tart taste at biological maturity. The ripening of berries was observed in the second decade of September. 
Population No.4. This population differs from the rest by the following traits: half-open young shoot apex, average degree of cotton and bristly pubescence of young shoot crown, as well as the lower and the upper side of the young and formed leaf, bristly pubescence of the internodes, almost rounded lamina with very small upper lateral cuts or with practical absence of them. Visually plants in this population also had a healthy appearance, no pests and diseases were found, fully flowered and fruited. The bunches were also small and very loose. Berries were small, juicy with a thick peel, black with a sweet and sour tart taste in biological maturity. Ripening- the second decade of September. The seeds are small, rounded, reddishbrown, on average 1-2 pcs. per berry.

Population No.5. Distinctive characteristics in the morphology of grape plants in this population: open apex (crown) of the young shoot, a weak degree of cotton and bristly pubescence of the young shoot crown, as well as the lower and upper sides of the young leaf, practical absence of pubescence on formed leaves, a deltoid lamina with weakly pronounced blades and very small upper lateral cuts. Plants in this population were visually healthy, at the time of studying there were no pests and diseases, fully flowered and fruited. Bunches of this population grape plants are small, loose. Berries are small, had a reddish-black color and a sour and sweet tart taste at biological maturity. The ripening of berries was observed in the second decade of September. The seeds are small, rounded, reddish-brown, on average 2-3 pcs. per berry.

As a result, more than 40 quantitative and qualitative morphological traits of vegetative and generative organs of agrestic grapes have been studied, some of which are most variable (Table 2).

Table 2. Inter-population variability of some quantitative morphological traits of vegetative organs of agrestic grapes (Red Forest Reserve, 2020)

\begin{tabular}{|l|l|l|l|l|l|l|}
\hline \multirow{2}{*}{ It.No. } & \multirow{2}{*}{ Trait } & \multicolumn{2}{|c|}{ Population number } & \multicolumn{1}{l|}{ K } \\
\cline { 3 - 6 } & & $\mathrm{K} 1$ & $\mathrm{~K} 2$ & $\mathrm{~K} 3$ & $\mathrm{~K} 4$ & \multicolumn{1}{l|}{ K } \\
\hline 1 & Leaf length, cm & $8.8 \pm 0.3$ & $7.7 \pm 0.3$ & $7.2 \pm 0.3$ & $8.5 \pm 0.3$ & $10.7 \pm 0.1$ \\
\hline 2 & Leaf width, cm & $8.7 \pm 0.2$ & $7.8 \pm 0.3$ & $8.5 \pm 0.3$ & $8.5 \pm 0.3$ & $8.9 \pm 0.2$ \\
\hline 3 & Petiole length, cm & $5.5 \pm 0.1$ & $5.5 \pm 0.1$ & $5.5 \pm 0.1$ & $5.7 \pm 0.1$ & $5.8 \pm 0.1$ \\
\hline 4 & $\begin{array}{l}\text { Internode length of young } \\
\text { shoot, cm }\end{array}$ & $5.1 \pm 0.4$ & $6.2 \pm 0.3$ & $7.0 \pm 0.2$ & $6.5 \pm 0.3$ & $6.2 \pm 0.3$ \\
\hline 5 & Number of leaf blades, pcs. & $5.0 \pm 0.01$ & $5.0 \pm 0.01$ & $3.0 \pm 0.01$ & $5.0 \pm 0.01$ & $5.0 \pm 0.01$ \\
\hline 6 & Length of leaf serratures, cm & $0.8 \pm 0.002$ & $0.5 \pm 0.001$ & $0.3 \pm 0.001$ & $0.5 \pm 0.001$ & $0.6 \pm 0.001$ \\
\hline 7 & Width of leaf serratures, cm & $0.6 \pm 0.002$ & $0.4 \pm 0.001$ & $0.4 \pm 0.001$ & $0.6 \pm 0.001$ & $0.6 \pm 0.001$ \\
\hline 8 & Leaf crimping* & $4.0 \pm 0.01$ & $3.0 \pm 0.01$ & $4.0 \pm 0.01$ & $5.0 \pm 0.01$ & $3.0 \pm 0.01$ \\
\hline 9 & Inflorescence length, cm & $10.2 \pm 0.2$ & $7.0 \pm 0.6$ & $6.8 \pm 0.6$ & $6.2 \pm 0.6$ & $8.8 \pm 0.4$ \\
\hline 10 & Berry length, cm & $0.9 \pm 0.002$ & $0.8 \pm 0.002$ & $0.7 \pm 0.002$ & $0.8 \pm 0.002$ & $0.9 \pm 0.002$ \\
\hline 11 & Berry width, cm & $0.9 \pm 0.002$ & $0.8 \pm 0.002$ & $0.7 \pm 0.002$ & $0.8 \pm 0.002$ & $0.9 \pm 0.002$ \\
\hline 12 & $\begin{array}{l}\text { Number of seeds per berry, } \\
\text { pcs. }\end{array}$ & $2.0 \pm 0.03$ & $1.0 \pm 0.07$ & $1.0 \pm 0.07$ & $2.0 \pm 0.07$ & $2.0 \pm 0.07$ \\
\hline
\end{tabular}

Note: * - the crimping degree of the upper side surface of the formed leaf is estimated in points on a 5-point scale, where 1 - absent, 2 - weak, 3 - medium, 4 - strong, 5 - very strong.

For example, the shape of young shoot apex (crown) varies in this case from open to halfopen. The cotton pubescence of the lower leaf side is from medium ( 3 points) to very thick ( 5 points), and the bristly pubescence of the formed leaf is from scarce to strong. Leaf shape is also largely variable at both inter-population and endogenous levels, it can be deltoid, pentagonal, or even rounded (Figure 1). 


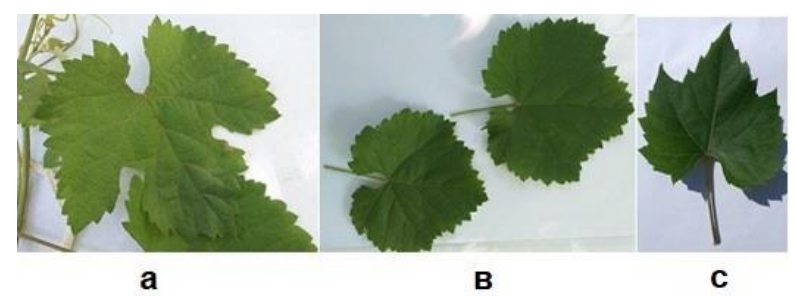

Fig. 1. Lamina shape in the studied agrestic species of the "Red Forest": A) pentagonal, B) rounded, C) deltoid

The depth of the upper lateral cuts is significantly variable from small and almost absent to very deep, which is also pronounced at the endogenous level. On a single grape plant, formed leaves with almost whole rounded lamina and dissected pentagonal or deltoid were found.

There was a variability of such traits as the anthocyanin coloration degree of the lower and upper sides and nodes of young shoots, as well as young shoots' crowns. The K1 and K5 populations had a pronounced anthocyanin coloration of the back side of shoots and nodes and a light degree of anthocyanin coloration of the apex of young shoots. In K2-K4 populations, these indicators were poorly expressed or absent at all, as for example, in the K3 population

The yield study of the studied agrestic forms was evaluated visually, while there were large amounts of bunches, which indicates their good productivity (Figure 2).

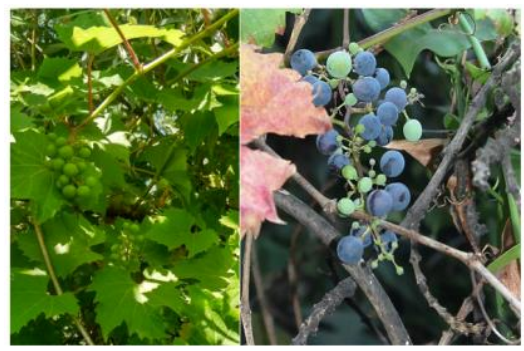

Fig. 2. Fruiting of agrestic grape forms (A - beginning of fruiting - July, B - full physiological maturity - September)

Bunches in the studied agrestic forms of grapes are often small and loose. Berries are also small, with a reddish-black and black coloration at biological maturity. The taste of the berries is sweet or sweet and sour tart, but with pleasant freshness. Ripening occurs in the second or third decade of September.

The presence of damage to agrestic grape populations by pests and diseases was not visually detected. In the future, these plants can be checked to identify new sources or donors of resistance to various biotic and abiotic environmental factors, including pathogenic microflora.

\section{Conclusions}

Expeditionary research carried out on the territory of the state natural reserve "Red Forest" allowed to study five isolated populations of agrestic grapes. For the first time, these forms were studied and described by the ecological and geographical growth conditions and morphological traits of vegetative and generative spheres of grape plants. When studying the morphology of their vegetative organs, the variability of some indicators was found. In particular, at the endogenous level, the lamina shape can be both pentagonal and round, the 
crimping degree of the upper lamina side varies from medium to strong, the young shoot apex openness degree - from completely open to half-closed, the pubescence degree of the young shoot crown - from medium to strong, as well as significantly varying indicators of leaves, serratures, internodes, etc.

At the inter-population level, significant variations in qualitative and quantitative morphological traits of the vegetative sphere of the studied agrestic grape plants are also observed. Such as, for example, the depth of the upper lateral cuts of lamina varies from small and almost absent to very deep. In the first case, the leaves have a rounded shape with small convex serratures (the serrature length is less than its width) or deltoid shape with sharp elongated serratures (the serrature length is greater than its width), and in the second case pentagonal with straight or directly convex serratures, which are approximately equal in length and width.

The practical lack of scientific information in the literature on agrestic and autochthonous Kuban grape forms gave a stimulus for conducting this kind of research. The obtained results of new scientific researches on ecological-biological and morphological features of agrestic Kuban grapes will allow to find out about their origin and identify new promising sources among them and later - resistance donors to various types of biotic and abiotic environmental factors. The ultimate goal of this long-term work is to attract agrestic sustainable forms in the breeding process and to replenish the gene pool of grape crop.

This research was carried out within the framework of the RFFR grant project (contract No.19-416-230025).

\section{References}

1. H.P. Olmo, The origin and ancient history of wine. Gor. and Bre, 31 (1995)

2. V. Alba, C. Bergamini, R. Genghi R. et al, Bio. Man., Mol. Bio. E., 57, 709 (2015)

3. J.S. Kanwar, I.S. Naruka, P.P. Singh, Ind. J. of Agr. Sci. E, 88(5), 737 (2018)

4. M.K. Aradhya, J. Preece, D.A. Kluepfel, Spec. Pap. Geol. Soc. Am. E., 1074, 95 (2015)

5. O. Failla, J. Grap. Res. E., 54, 1 (2015)

6. S.M. Gorislavets, V.I. Risovannaya, Ya.A. Volkov, A.A. Kolosova, V.A. Volodin, Vit. and win. E., 1, 19 (2017)

7. A.M. Adzhiev, A.A. Zarmaev, S.A. Adzhieva, Vin. and vit. E., 6, 36 (2015)

8. V.A. Ganich, L.G. Naumova, N.V. Matveeva, Plod. and ber. grov. Rus. E., 54, 139 (2018)

9. E.T. Ilnitskaya, S.V. Tokmakov, I.I. Suprun, M.V. Makarkina, GNU ncrrih V. E. 31(1), $13(2015)$

10. I.V. Gorbunov, E.T. Ilnitskaya, A.A. Lukyanov, S.S. Mikhailovsky, M.V. Makarkina, M.I. Pankin, O.N. Bykhalova, IOP Conf. Ser. E., 548 (2020)

11. I.V. Gorbunov, S.S. Mikhailovsky, O.N. Bykhalova, Web of Conf. (2020)

12. A.M. Lavrenko, A.A. Korchagin, Fil. geob. E, 3, 530 (1964)

13. M.A. Lazarevsky, Study of grape varieties (1963)

14. E.T. Il'nitskaya, I.V. Gorbunov, M.V. Makarkina, S.V. Tokmakov, S.S. Mikhaylovskiy, M.I. Pankin, Plod. and vin. Sou. Rus. E., 62(2), 14 (2020)

15. I.V. Gorbunov, A.A. Luk'yanov, O.N. Bykhalova, Plod. and vin. Sou. Rus. E., 65(5), 70 (2020) 